\begin{tabular}{|c|c|c|}
\hline \multirow{2}{*}{$\begin{array}{r}\text { Case Reports in } \\
\text { Gastroenterology }\end{array}$} & \multicolumn{2}{|c|}{ Case Rep Gastroenterol 2018;12:260-265 } \\
\hline & $\begin{array}{l}\text { DOI: 10.1159/000489299 } \\
\text { Published online: June 15, } 2018\end{array}$ & $\begin{array}{l}\text { (c) } 2018 \text { The Author(s) } \\
\text { Published by S. Karger AG, Basel } \\
\text { www.karger.com/crg }\end{array}$ \\
\hline & $\begin{array}{l}\text { This article is licensed under } t \\
\text { International License (CC BY-NC } \\
\text { Usage and distribution for comm }\end{array}$ & $\begin{array}{l}\text { mons Attribution-NonCommercial } 4.0 \\
\text { ger.com/Services/OpenAccessLicense). } \\
\text { guires written permission. }\end{array}$ \\
\hline
\end{tabular}

\title{
Pemphigus Vulgaris in the Mouth and Esophageal Mucosa
}

\author{
Angelo Gualberto de Macedo ${ }^{a}$ Erika Ruback Bertges ${ }^{b}$ \\ Luiz Carlos Bertges $^{\mathrm{b}} \quad$ Renata Alvim Mendes ${ }^{\mathrm{b}}$ \\ Thais Abranches Bueno Sabino Bertges ${ }^{b} \quad$ Klaus Ruback Bertges ${ }^{c}$ \\ Fernando Monteiro Aarestrup ${ }^{c}$ \\ aSanta Casa de Misericórdia de Piumhi, Piumhi, Brazil; bospital Therezinha de Jesus, \\ Faculty of Medical Sciences and Health of Juiz de Fora, Juiz de Fora, Brazil; 'Stricto Sensu \\ Postgraduate in Health, Federal University of Juiz de Fora, Juiz de Fora, Brazil
}

\section{Keywords}

Pemphigus · Pemphigus vulgaris · Esophagus · Endoscopy · Histopathology

\begin{abstract}
Pemphigus vulgaris (PV) is a chronic autoimmune mucocutaneous disease. In most cases, the initial manifestation occurs in the mouth as multiple ulcerations preceded by blisters that rupture and later spread to other mucous membranes and the skin. Esophageal impairment is rare. We report a case of PV with esophageal involvement in a 53-year-old woman who sought medical care, complaining of diffuse painful lesions in the oral cavity for approximately 1 month, with no improvement with nystatin. Upper digestive endoscopy (UDE) was performed with findings of vesiculobullous lesions in the proximal and middle esophagus, which were biopsied and for which histopathology confirmed PV in the esophageal mucosa. We draw attention to UDE as important for the diagnosis, and it should be indicated in patients with vesiculobullous lesions of the mouth, especially if there are esophageal complaints.
\end{abstract}




\section{Introduction}

Pemphigus is defined as a set of pathological entities of autoimmune etiology, of rare incidence, characterized by the formation of intraepithelial blisters on the skin and mucous membranes. There are four main types of pemphigus: foliaceus, erythematosus, vulgaris, and vegetative [1]. Pemphigus vulgaris (PV) is the most common of these, despite its rare occurrence, with an estimated incidence in the general population of 1-5 cases per million people diagnosed each year [2]. It rarely occurs before the third decade of life, the mean age at diagnosis being 50 years, although rare cases can be seen in childhood.

The etiopathogenesis of PV is not yet fully understood; however, the authors are unanimous in affirming its autoimmune nature, evidenced by the presence of autoantibodies specific for the stratified squamous epithelium [3]. The primary site of the disease is the intercellular cement of the Malpighi spinous layer, although it is not known why this cement becomes antigenic and induces the production of autoantibodies, mainly of the IgG type. IgG autoantibodies, more specifically IgG1 and IgG4, act against the glycoproteins desmoglein 1 and desmoglein 3, which belong to the family of cadherins and are located in the desmosomes of the epithelium of the skin and mucosa or are present in the sera of affected patients. Such antibodies promote the rupture of the intercellular bridges, and, as a consequence, the cells lose their adhesion with the formation of intraepithelial clefts, which characterizes the phenomenon of acantholysis. The antigen-antibody binding induces the activation of proteinases, particularly activated plasminogen, which transforms into plasmin after being released by keratinocytes, promoting the lysis of the intercellular substance [4]. The participation of genetic factors in the predisposition to PV was observed from studies in which it was evidenced that the expression of histocompatibility antigen HLA-A26 seems to predispose the individual to disease development. However, the presence of endogenous factors such as immunological molecules and exogenous defects such as viruses, drugs, and physical agents is necessary for PV development [5]. The study by Frusic-Zlotkin et al. [5] demonstrated that apoptotic mechanisms may be present in the acantholysis process.

There are very few publications on PV involving the esophagus. In a Medline search with the descriptors Pemphigus [ti] esophagus and dysphagia, only 12 publications were found.

Our objective is to report the case of a female patient with oral lesions and esophageal impairment diagnosed by endoscopy and histopathology such as PV.

\section{Case Report}

A 53-year-old female patient sought medical care due to diffuse lesions on the oral mucosa (lips, tongue, and especially the palate and cheek region). These lesions had been developing for approximately 30 days without improvement with the use of nystatin. They were hyperemic and diffuse, with areas covered by "whitish membranes," in addition to intense friability, with spontaneous bleeding and pain. She reported unquantified weight loss and an oral mucosa swab was performed during the investigation for fungus research, with a positive result. Laboratory exams revealed no alterations (including HIV negativity), except for eosinophilia, with a total leukometry of 7,500 and 14\% eosinophils. Itraconazole $200 \mathrm{mg} /$ day was initiated. As there was no clinical improvement, the medication was replaced with fluconazole $150 \mathrm{mg} /$ day, with no satisfactory result. Upper digestive endoscopy (UDE) was then performed, and esophageal lesions were observed that were similar to those observed in the oral 


\section{Case Reports in Gastroenterology}

Case Rep Gastroenterol 2018;12:260-265

DOI: 10.1159/000489299

(c) 2018 The Author(s). Published by S. Karger AG, Basel www.karger.com/crg

de Macedo et al:: Pemphigus Vulgaris in the Mouth and Esophageal Mucosa

mucosa, especially in the proximal third, decreasing in the middle third, and absent in the distal third (Fig. 1,2). Biopsies were collected, and a histopathological diagnosis of PV was established. Prednisone was initiated, with clinical and endoscopic improvements (Fig. 3). At the moment, she is in outpatient follow-up.

\section{Discussion}

In PV, the initial lesions are formed by the rupture of asymptomatic blisters with thin walls that leave an area of erosion or painful ulceration [6]. In approximately 70-90\% of cases, signs of the disease appear initially in the buccal mucosa and are most commonly found in the areas subject to frictional trauma [7].

Involvement of the esophagus is rare, but some studies have reported more frequent involvement than previously thought [8]. By endoscopically examining the esophagi of PV patients, Calka et al. [9] found up to $46.15 \%$ of esophageal involvement. Mignogna et al. [10] found esophageal involvement in 5 out of 8 patients examined. In cases where there is esophageal involvement, the main symptoms are dysphagia and odynophagia, present in 57.1 and $21.4 \%$ of cases [10,11]. Bleeding is even rarer, in $3.5 \%$ of cases [12].

We presented an unusual case of vesiculobullous lesions in the buccal region and proximal esophagus, the diagnosis of which was made possible by UDE, which was determinant for adequate therapy and clinical improvement of the patient. Our patient did not present relevant esophageal symptoms other than anorexia and weight loss. The symptoms were predominantly oral and did not improve with the usual treatment for diagnoses of oral candidiasis, which was administered initially.

The lesions, as in our case, usually concomitantly reach the mouth and the esophagus; however, some authors have shown involvement of the esophagus only [13].

Esophageal involvement is more frequently diagnosed when there are symptoms such as dysphagia and odynophagia, with a previous history of PV, especially if the patient is not responsive to the usual treatment [14]. The majority of patients with lesions in the esophagus are middle-aged women, as in our case [14].

In our case, the patient had an initial diagnosis of moniliasis performed by oral swab and was treated as such, but she did not respond adequately. Once the endoscopy was performed and PV was diagnosed, it effectively responded to oral corticosteroid therapy.

We conclude that in patients with vesiculobullous oral lesions, PV should be considered as one of the diagnostic hypotheses. Although esophageal involvement seems to be rare, it has been identified in many patients, even without oral involvement. The accomplishment of UDE with the performance of biopsies and histopathology is fundamental for diagnostic clarification.

\section{Statement of Ethics}

Approval from the ethics committee was obtained from the Faculty of Medical Science and Health of Juiz de Fora MG - Brazil, No. 2.570.661, for this case report. Besides that, written informed consent was obtained from the patient for publication of this case report and any accompanying images. 


\section{Case Reports in Gastroenterology}

\section{Disclosure Statement}

The authors have no conflicts of interest to declare.

\section{Funding Sources}

There were no sources of financial support for this study.

\section{References}

1 Camacho-Alonso F, López-Jornet P, Bermejo-Fenoll A. Pemphigus vulgaris. A presentation of 14 cases and review of the literature. Med Oral Patol Oral Cir Bucal. 2005 Aug-Oct;10(4):282-8.

2 Robinson JC, Lozada-Nur F, Frieden I. Oral pemphigus vulgaris: a review of the literature and a report on the management of 12 cases. Oral Surg Oral Med Oral Pathol Oral Radiol Endod. 1997 Oct;84(4):349-55.

3 Heaphy MR, Albrecht J, Werth VP. Dapsone as a glucocorticoid-sparing agent in maintenance-phase pemphigus vulgaris. Arch Dermatol. 2005 Jun;141(6):699-702.

4 Joly P, Richard C, Gilbert D, Courville P, Chosidow O, Roujeau JC et al. Sensitivity and specificity of clinical, histologic, and immunologic features in the diagnosis of paraneoplastic pemphigus. J Am Acad Dermatol. 2000 Oct;43(4):619-26.

5 Frusic-Zlotkin M, Pergamentz R, Michel B, David M, Mimouni D, Brégégère F et al. The interaction of pemphigus autoimmunoglobulins with epidermal cells: activation of the fas apoptotic pathway and the use of caspase activity for pathogenicity tests of pemphigus patients. Ann N Y Acad Sci. 2005 Jun;1050(1):371-9.

6 Chi AC, Ravenel MC, Neville BW, Bass EB Jr. A patient with painful oral ulcers. J Am Dent Assoc. 2006 May;137(5):626-9.

7 Tan SR, McDermott MR, Castillo CJ, Sauder DN. Pemphigus vulgaris induced by electrical injury. Cutis. 2006 Mar;77(3):161-5.

8 Al-Janabi A, Greenfield S: Pemphigus vulgaris: a rare cause of dysphagia. BMJ Case Rep 2015;2015:bcr2015212661.

9 Calka O, Akdeniz N, Tuncer I, Metin A, Cesur RS. Oesophageal involvement during attacks in pemphigus vulgaris patients. Clin Exp Dermatol. 2006 Jul;31(4):515-9.

10 Mignogna MD, Lo Muzio L, Galloro G, Satriano RA, Ruocco V, Bucci E. Oral pemphigus: clinical significance of esophageal involvement: report of eight cases. Oral Surg Oral Med Oral Pathol Oral Radiol Endod. 1997 Aug;84(2):179-84.

11 Cecinato P, Laterza L, De Marco L, Casali A, Zanelli M, Sassatelli R. Esophageal involvement by pemphigus vulgaris resulting in dysphagia. Endoscopy. 2015;47(Suppl 1 UCTN):E271-2.

12 Chang S, Park SJ, Kim SW, Jin MN, Lee JH, Kim HJ et al. Esophageal involvement of pemphigus vulgaris associated with upper gastrointestinal bleeding. Clin Endosc. 2014 Sep;47(5):452-4.

13 Kamm MA, Brenan JA, Davies DJ, Desmond PV. Pemphigus vulgaris of the esophagus. J Clin Gastroenterol. 1988 Jun;10(3):324-6.

14 Goldberg NS, Weiss SS. Pemphigus vulgaris of the esophagus in women. J Am Acad Dermatol. 1989 Nov;21(5 Pt 2):1115-8. 


\section{Case Reports in Gastroenterology}

\begin{tabular}{l|l}
\hline Case Rep Gastroenterol 2018;12:260-265 \\
\hline DOI: 10.1159/000489299 & $\begin{array}{l}\text { @ 2018 The Author(s). Published by S. Karger AG, Basel } \\
\text { www.karger.com/crg }\end{array}$ \\
\hline
\end{tabular}

de Macedo et al.: Pemphigus Vulgaris in the Mouth and Esophageal Mucosa

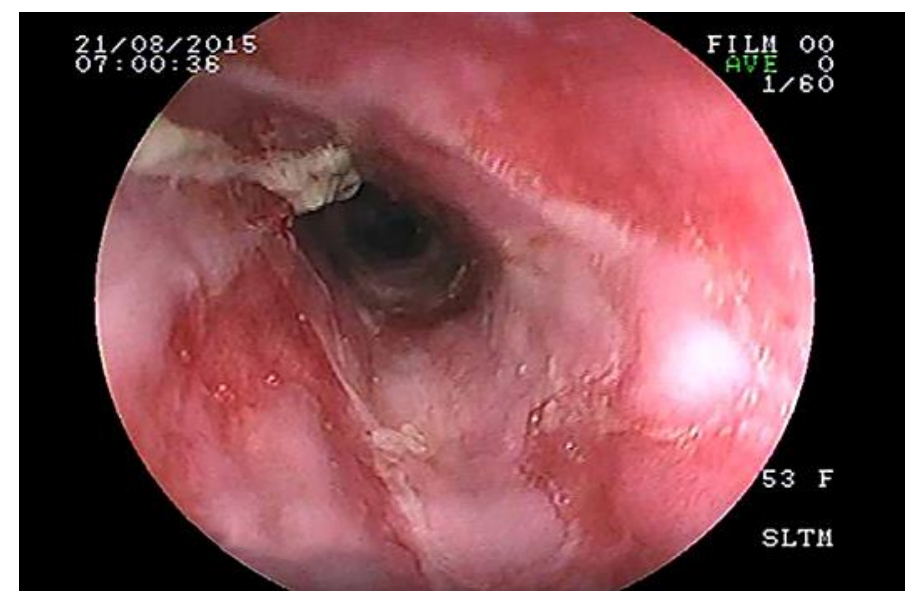

Fig. 1. Lesion in epiglottis identified during endoscopy, before treatment with prednisone.

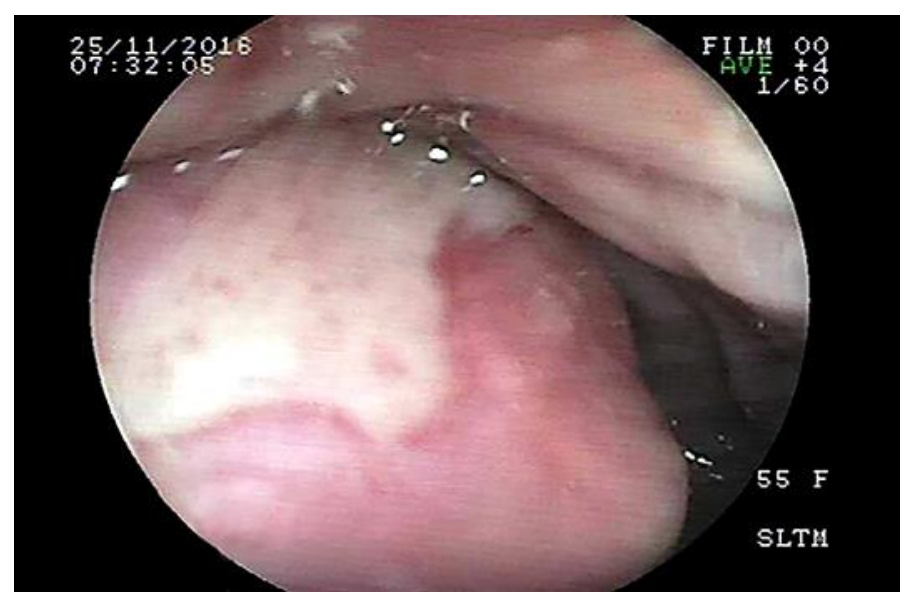

Fig. 2. Esophageal lesion identified during endoscopy, before treatment with prednisone. 


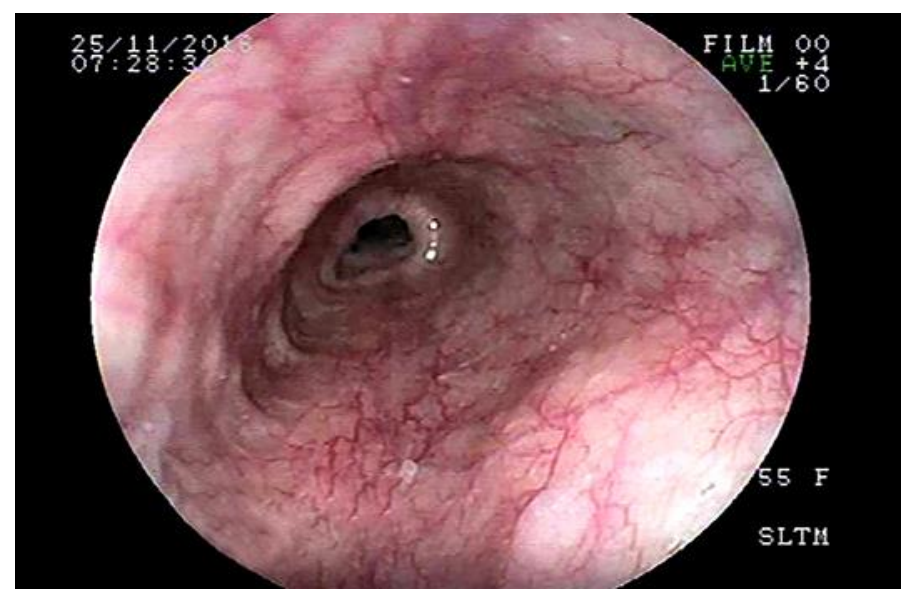

Fig. 3. Image of the esophagus, after treatment with prednisone. 